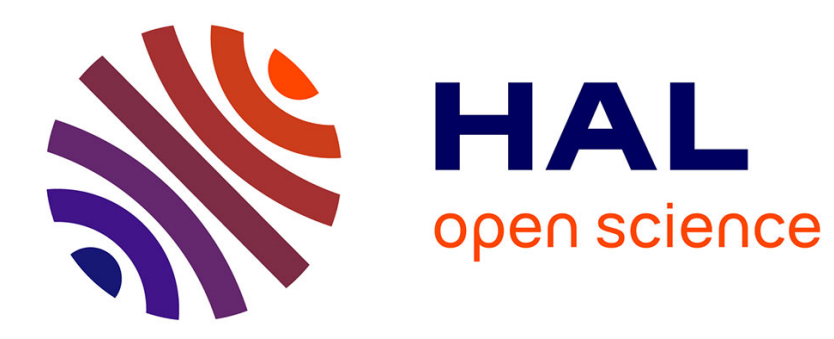

\title{
Climate policies in a second-best world- a case study on India
}

\author{
Sandrine Mathy, Céline Guivarch
}

\section{To cite this version:}

Sandrine Mathy, Céline Guivarch. Climate policies in a second-best world- a case study on India. Energy Policy, 2010, 38 (3), pp.1519-1528. 10.1016/j.enpol.2009.11.035 . halshs-00724498

\section{HAL Id: halshs-00724498 \\ https://shs.hal.science/halshs-00724498}

Submitted on 21 Aug 2012

HAL is a multi-disciplinary open access archive for the deposit and dissemination of scientific research documents, whether they are published or not. The documents may come from teaching and research institutions in France or abroad, or from public or private research centers.
L'archive ouverte pluridisciplinaire HAL, est destinée au dépôt et à la diffusion de documents scientifiques de niveau recherche, publiés ou non, émanant des établissements d'enseignement et de recherche français ou étrangers, des laboratoires publics ou privés. 


\title{
Climate policies in a second-best world- a case study on India
}

\author{
Sandrine Mathy ${ }^{\mathrm{a},{ }^{*}}$, Céline Guivarch ${ }^{\mathrm{a}}$
}

a Centre International de Recherche sur l'Environnement et le Développement, Nogent-sur-Marne, France

* Corresponding author at: CIRED, 45bis, Av. de la Belle Gabrielle, F-94736 Nogentsur-Marne, France.

Tel.: +331439473 96; fax: +33143947370.

E-mail address: mathy@ centre-cired.fr (S. Mathy)

Reference to this paper should be made as follows: Mathy, S., Guivarch, C. 2010. 'Climate policies in a second-best world - A case study on India', Energy Policy 38:3, 1519-1528.

\begin{abstract}
The aim of this article is to analyze the potential for synergies between climate policies and development in a case study on India focusing on the power sector suboptimalities. To do so, we use IMACLIM-R, a dynamic recursive energy-economy model that represents a second best world with market imperfections and short-run adjustments constraints along a long-term growth path. The analysis suggests (i) global carbon pricing induces prohibitive macroeconomic costs for the Indian economy, even in the case of significant financial transfers associated with a global cap-and-trade system and a "Contraction and Convergence in 2100" allocation scheme; (ii) the most cost efficient climate policies are not uniform carbon pricing only. The implementation of domestic policies suited to the national context, for instance targeting sub-optimalities in the power sector for India, allows reducing significantly the macroeconomic costs induced by international mitigation policies.
\end{abstract}

\section{Keywords}

India, second-best world, synergies between climate mitigation and development 


\section{Introduction}

There is now a global scientific consensus that stringent GHG emissions reductions are necessary to limit the high risks associated with anthropogenic climate change, and this consensus is flagged as a long run collective target by an increasing number of policymakers from all countries (G8 declaration in l'Aquila in July $2009^{1}$, China $^{2}$ and $\operatorname{Japan}^{3}$ Statements at the United Nations Climate Summit, 2009). But translating this long run target into an international agreement stumbles over the common argument that climate policies would harm economic growth, and in particular slow the development of emerging and developing countries.

The assessments of climate policies costs provide reassuring messages: the global macroeconomic mitigation cost is estimated below five percent of GDP in 2050, even for the most stringent emission constraints (IPCC 2007). In addition, a majority of economic analyses recommend a uniform carbon tax or a universal cap and trade system equalizing marginal abatement costs across countries as the most efficient policy (for instance Manne and Richels, 1997 or Weyant and Hill, 1999).

\footnotetext{
1 "We recognise the broad scientific view that the increase in global average temperature above preindustrial levels ought not to exceed $2^{\circ} \mathrm{C}$. Because this global challenge can only be met by a global response, we reiterate our willingness to share with all countries the goal of achieving at least a 50\% reduction of global emissions by 2050, recognising that this implies that global emissions need to peak as soon as possible and decline thereafter. As part of this, we also support a goal of developed countries reducing emissions of greenhouse gases in aggregate by $80 \%$ or more by 2050 compared to 1990 or more recent years"

2 "We will endeavor to cut carbon dioxide emissions per unit of GDP by a notable margin by 2020 from the 2005 level [...] We will endeavor to increase the share of non fossil fuels in primary energy consulmption to around $15 \%$ by $2020 "$ ". (Jintao, 2009)

3 "For its mid-term goal, Japan will aim to reduce its emissions by $25 \%$ by 2020 , if compared to the 1900 level, consistent with what the science calls for in order to halt global warming". ( Hatoyama, 2009)
} 
However these results are submitted to the critical caveat that most models used to analyze the climate change economics issues represent a first best world (optimizing agents with perfect foresight, market-clearing equilibrium in all markets, full utilisation of production factors), as specified in Box SPM-3 of last IPCC assessment report: 'Most models use a global least cost approach to mitigation portfolios and with universal emissions trading, assuming transparent markets, no transaction cost, and thus perfect implementation of mitigation measures throughout the 21 st century'. Such assumptions can be suspected of underestimating mitigation costs, making modelling results 'too good to be true' as Stavins et al (2007) argue in an examination of three economic assessments of California climate change policy. Moreover, any deviation from the assumed optimal equilibrium to accommodate environmental policies will by definition lead to costs in models representing a first best world (Barker et al, 2002). Therefore, these methodological choices exclude by construction the possibility of synergies between environmental policies and development policies, and thus prevent from analyzing this issue. Nevertheless, real economies are characterised by numerous imperfections contrasting with the first best representation in most environmentenergy-economy (E3) models. These imperfections can lead to higher mitigation costs than estimated as Guivarch et al. (2009) showed in the case of labour markets rigidities. But they can also provide opportunities for synergies between climate change mitigation and economic growth.

The aim of this article is to analyze the potential for synergies between climate policies and development in a case study on India focusing on the power sector suboptimalities. To do so, we use IMACLIM-R a dynamic recursive energy-economy model that represents a second best world with market imperfections and short-run 
adjustments constraints along a long-term growth path. The first section describes this modelling framework, and details how the Indian power sector sub-optimalities are represented in this framework. The second section analyses the macroeconomic impacts for India of international climate policies, in the form of a worldwide coordinated carbon tax or through a global cap-and-trade system. We disentangle the mechanisms explaining why global carbon pricing induces prohibitive macroeconomic costs for the Indian economy, even in the case of significant financial transfers associated with a "Contraction and Convergence in 2100" allocation scheme. The third section analyses a 'package of domestic policies and measures' implemented in India jointly with the participation to the global cap-and-trade system, and focused on combining (i) electricity tariff reforms in the agricultural sector accompanied by demand side management measures, and (ii) efficiency of the power sector. We show that this package of domestic policies and measures allows reducing significantly both the duration and the magnitude of India GDP losses following the introduction of the global cap-and-trade system. While, the second and third sections focus on disentangling the mechanisms leading to our results, the fourth section examines the robustness of results through sensitivity tests. Last section concludes. Conclusions are twofold (i) from a methodological point of view, considering second best mechanisms and sub-optimalities arising in the real world in a modelling framework opens the possibility to study potentials for synergies between mitigation policies and development; (ii) from a policy point of view, the most cost efficient climate policies are not uniform carbon pricing only. The implementation of domestic policies suited to the national context, for instance for India targeting sub-optimalities in the power sector, allows reducing significantly the macroeconomic costs induced by international mitigation policies. 


\section{A modelling framework to represent a second best world}

\subsection{Model architecture and major features}

\subsubsection{A hybrid recursive framework to account for inertia in technical systems and sub-optimalities}

IMACLIM-R is a hybrid recursive general equilibrium model of the world economy that is split into 12 regions and 12 sectors (Sassi et al. 2007).

It is hybrid in two senses. First, it is a hybrid model in the classical sense: its structure is designed to combine Bottom-Up information in a Top-Down consistent macroeconomic framework. Energy is explicitly represented in both money metric values and physical quantities so as to capture the specific role of energy sectors and their interaction with the rest of the economy. The existence of explicit physical variables allows indeed a rigorous incorporation of sector based information about how final demand and technical systems are transformed by economic incentives.

Second, it is hybrid in the sense of Solow $(2000)^{4}$, i.e. it tries and bridges the gap between long-run and short-run macroeconomics, as efforts were devoted not only to model long-term mechanisms but also focus on transition and suboptimal pathways through possible underutilization of production factors. We seek, indeed, to capture the transition costs with a modeling architecture that allows for endogenous disequilibrium generated by the inertia in adapting to new economic conditions due to both imperfect foresight and non flexible characteristics of equipment vintages

\footnotetext{
${ }^{4}$ Solow (2000): 'I can easily imagine that there is a «true » macrodynamics, valid at every time scale. But it is fearfully complicated [...] At the five-to-ten-year time scale, we have to piece things together as best we can, and look for a hybrid model that will do the job.'
} 
available at each period (putty-clay technologies). In the short run the main available flexibility lies in the rate of utilization of capacities, which may induce excess or shortage of production factors, unemployment and unequal profitability of capital across sectors. Therefore, the model architecture departs from the picture of a first best world.

Technically, the model can be labelled as 'recursive dynamic', since it generates an energy-economy trajectory by solving successive yearly static equilibria of the economy, interlinked by dynamic modules.

Within the static equilibrium, domestic and international markets for all goods except factors such as capital and labour - are fully cleared by a unique set of relative prices that depend on the behaviours of representative agents on the demand and supply sides. The calculation of this equilibrium determines the following variables: relative prices, wages, employment, quantities of goods and services, value flows. Within each yearly static equilibrium, the behaviour of producers is not represented by a flexible production function allowing for substitution between factors. These substitutions are treated between two equilibria in sector-specific dynamic modules. Producers are therefore assumed to operate under short-run constraints of (i) a fixed maximal production capacity $\operatorname{Cap}_{k, i}$, defined as the maximum level of physical output achievable with the equipment built and accumulated previously, and (ii) fixed inputoutput coefficients representing that, with the current set of embodied techniques, producing one unit of a good $i$ in region $k$ requires fixed physical amounts $I C_{j, i, k}$ of intermediate goods $j$ and $l_{k, i}$ of labour. In this context, the only margin of freedom of producers is to adjust the utilisation rate $Q_{k, i} / \operatorname{Cap}_{k, i}$ according to the relative market prices of inputs and output, taking into account increasing costs when the production 
capacities utilization rate approaches one ${ }^{5}$. This represents a different paradigm from usual production specifications, since the 'capital' factor is not always fully operated. The dynamic modules shape the accumulation of capital and its technical content, they are driven by economic signals, such as prices or sectoral profitability, that emerge from former static equilibriums. They include the modelling of (i) the evolution of capital and energy equipment stock described in both vintage and physical units (such as number of cars, housing square meter, transportation infrastructure), (ii) of technological choices of economic agent described as discrete choices in explicit technology portfolios for key sectors such as electricity, transportation and alternative liquid fuels, or captured through reduced form of technology rich bottom up models, and (iii) of endogenous technical change for energy technologies (with learning curves).

\subsubsection{A growth engine allowing gaps between potential growth and effective}

\section{growth}

Our model growth engine is composed of:

(i) exogenous demographic trends. The demographic assumptions are drawn from the United Nations World Population Prospects "median variant" scenario (United Nations 2005).

(ii) technical progress that increases labour productivity, as in Solow's neoclassical model of economic growth (Solow, 1956). We use exogenous trends of productivity growth, as it is a common practice in the energy-environment modelling community (e.g. Edmonds et al., 2004, Paltsev et al., 2005). To build these trends we draw on

\footnotetext{
${ }^{5}$ Mean generation costs increase when capacity utilisation approaches one due to the existence of static decreasing returns due to higher labour costs and because less efficient units are switched on last at the aggregate level. By default, following Corrado and Mattey (1997), in our model the increasing factor is attached to wages.
} 
stylized facts from the literature, in particular the convergence assumption (Barro and Sala-i-Martin 1992) and two empirical analyses on economic convergence, one investigating the past trends by (Maddison 1995), and the other one looking at future trends, by (Martins et al. 2005). We retained a "leader", the US, whose labor productivity growth trend lies between $2 \%$ today and $1.65 \%$ in the long run. The other regions labor productivity trends catch up with the leader's, i.e. their labor productivity growth is higher all the more as their absolute labor productivity is far from the leader's level.

These two sets of assumptions on demography and technical change, although exogenous, only prescribe potential growth. For India, potential growth decreases from $8 \%$ to $2.7 \%$ over the 2050 time horizon. Effective growth results endogenously from the interaction of these driving forces with short-term constraints: (i) available capital flows for investments and (ii) rigidities, such as fixed technologies, immobility of the installed capital across sectors or rigidities in real wages, which may lead to partial utilization of production factors (labor and capital).

\subsubsection{Calibration}

Our model is calibrated on 2001 data from GTAP 6 database (Dimaranan et McDougall 2002) that provides, for the year 2001, a set of balanced input-output tables of the world economy, detailed in 87 regions and 57 sectors. We modified the original GTAP-6 dataset (i) to aggregate regions and sectors according to the IMACLIM-R mapping (Table 1) (ii) to make it fully compatible with the 2001 IEA energy balances ${ }^{6}$.

\footnotetext{
${ }^{6}$ This process of building hybrid input-output matrices is very precisely discussed in (Sands, Miller and Kim 2005).
} 

industry)

Table 1: Regional and sectoral disaggregation of the IMACLIM-R model

In the two following subsections we describe how specific sub-optimalities of the Indian power sector can be embarked within the Imaclim-R model.

\subsection{Sub-optimalities in the power sector in India}

India is characterized by a restrained access to electricity services for both households and productive sectors. In 2007, capacity shortage was estimated to $10 \mathrm{GW}$ (14.8\% of peak power) and the gap between supply and demand reached 66 TWh $(9.6 \%$ of total demand). Electrification covers only $60 \%$ of Indian households. The remaining $40 \%$ mainly on traditional biomass or on diesel generators for their energy needs. Productive sectors are also affected by power cuts, which hinder productivity and development, in particular for industry, and force the use of diesel generators as well. Power cuts and capacity shortage are caused by structural under-investment in the power sector, rooted between market and institutional failures. The opening of the sector to independent power producers began in 1991 in order to absorb the shortage and to compensate for the constraints on public funding. But it failed to improve significantly the situation and the private sector contributes only to $11 \%, 0.4 \%$ and 
$12 \%$ of total generation, transport and distribution respectively. In 2008 , realized investments in the power sector equal to 14 billion US\$ and 21.5 billion US\$ would be needed to respond to total demand (i.e. the investment gap is equal to 7.5 billion US\$ or $35 \%$ of estimated needs for investments). During the $10^{\text {th }}$ Plan implementation period (2002 - 2007), less than half of the additional power capacity that had been programmed, has actually been built. This under-investment is largely due to the high risks and low profitability of investments in the power sector. Administered prices do not cover production costs: in 2006, the average price of electricity sold covered only $77 \%$ of the average production cost. Official data (Government of India, 2008) estimate the total under-recovery of costs to 431 billion rupees in 2008 (i.e. 8.8 US\$ billion). The same report estimates that the residential tariff covers $56 \%$ of the generation costs and farmers tariff only $12 \%$, while industries and the commercial sector partly compensate by paying respectively $108 \%$ and $122 \%$ of production costs. Official data reports that subsidies to household electricity consumption tripled to 80.8 billion rupees (US\$ 1.7 billion) between 1992-1993 and 1999-2000. Subsidies to agriculture electricity consumption more than tripled to 227 billion rupees (4.7 US\$ billion, $1.1 \%$ of Indian GDP) over the same period. In 2000, agriculture electricity uses represented one third of electricity sales in volume while the corresponding revenues constituted only 4 or $5 \%$ of total revenues.

These subsidies are justified by positive externalities on development, particularly regarding access to cheap energy for irrigation in an effort to promote food production (Tongia and Banerjee, 1998). Nonetheless, they have significant side effects. First, the very low tariffs for farmers induce overconsumption, which increases the magnitude of capacity shortage. Dorin and Jullien (2004) estimate that overconsumption of electricity in the agricultural sector amounts to $30 \%$ of its consumption due to the 
combination of critically low prices and of frequent but unpredictable power cuts that create a strong incentive to a continuous use of electric pumps for irrigation. Second, low revenues from electricity sales induce maintenance under-financing and increasing inefficiencies in transmission and distribution (T\&D). Technical and commercial T\&D losses have increased from around $20 \%$ in 1993 to more than $30 \%$ in 2001 (Thakur et al., 2006) $)^{7}$.

Moreover, power sector inefficiencies constrain economic activity and economic growth: electricity shortages hamper productivity and competitiveness.

It appears that the sub-optimalities of the Indian power sector described above are structural characteristics of the Indian energy system. Therefore, they have to be taken into account in modelling framework to develop realistic prospective scenarios, as advocated almost fifteen years ago by Shukla (1995) and more recently by Urban et al (2007) and Van Ruijven et al (2008). Next section describes how stylised representations of these sub-optimalities are introduced in our modelling framework.

\subsection{Representing market and institutional failures of the power sector in our modeling architecture}

In the static equilibriums, the electricity price depends on the characteristics of the installed power generation capacities (the type of fuel used and the efficiency, including T\&D losses) and on the utilization rate of these generation capacities: high utilization rates induce extra-costs. Between each static equilibrium, the evolution of

\footnotetext{
${ }^{7}$ The level of T\&D losses is in fact uncertain. For instance, the value stated by the Indian Planning Commission was $22 \%$ in 1998 while the World Bank (1998) pointed out that it could actually be twice this official level. Moreover, as there is no metering of the electricity consumption it is difficult to distinguish technical from commercial losses.
} 
power generation capacities is represented as follows: when describing annual investment decisions within the electric sector, the model anticipates, ten years forward, the potential future demand for electricity, taking into account past trends of demand. The module then computes an optimal mix of electric productive capacities to face the future demand at the lowest cost given (imperfect) anticipations of future fuel prices, including carbon pricing if applicable. The share of each technology in the optimal capacity mix results from a classical competition among available technologies depending on their mean total life-cycle costs (fixed costs, variable costs, investment costs). In practice, 26 producing technologies are in competition according to a non flat load curve.

Once the optimal mix of productive equipment for year $t+10$ has been computed, the model accounts for the time constraints in the deployment of capacities: the new capacity built at year $t$ results from a minimization of the gap between the mix of capacity currently installed and the mix of capacity that is expected to be optimal to face the demand at year $t+10$. This minimization is run under the constraint of the actual amount of investment allocated to the electric sector. This process of planning with imperfect foresight is repeated at every period and anticipations are adapted to changes in prices and demand.

Within this modelling framework, specificities of the Indian power sector namely (i) power generation capacity shortage, (ii) under-investment, (iii) tariffs not reflecting costs and subsidies to electricity consumption for farmers and households and (iv) inefficiencies and T\&D losses, are embarked.

(i) Power generation capacity shortage is represented by over utilization of generation capacities. In the model, a utilization rate superior to 0.8 means that the capacity is 
overused. In 2008, the utilization rate of electricity production capacities is 0.86 , which corresponds to $7.5 \%$ of capacity shortage (i.e. $7.5 \%$ more capacities would be needed to reach a utilization rate of 0.8 ) and is consistent with estimations given in the first section. This over utilization of productive capacities entails extra generation $\operatorname{costs}^{8}$ and raises the electricity usage cost, which is a stylized representation of electricity shortage (power cuts) for the Indian economy.

(ii) Under-investment in the power sector is represented by a gap between the estimated need of investments and realized investments in the power sector. Realized investments for all sectors are constrained by sectors profitability and total domestic investment plus net capital inflows.

(iii) Tariffs and subsidies for all commodities, including electricity, are encompassed in the sectors cost structure of the Social Accounting Matrix for India from GTAP-6 database (Dimaranan and McDougall, 2002) that is used to calibrate our model on the year 2001 .

(iv) Power plants characteristics, in particular their efficiencies, as well as transmission and distribution losses are calibrated on the sectoral model POLES (LEPII-EPE, 2006). In 2001, the calibration date, overall efficiency of power generation is equal to $32 \%$ and Transmission and Distribution losses are $35 \%$.

In sections 2 and 3, we investigate different Indian climate policies and their impact on economy. Within the following scenarios, the tariffs and subsidies structure for all commodities, including electricity, is by default kept unchanged through the entire time horizon. Moreover, without specific policies, the electricity transmission and

\footnotetext{
${ }^{8}$ Mean generation costs increase when capacity is overused due to the existence of static decreasing returns due to higher labour costs and because less efficient units are switched on last at the aggregate level. By default, following Corrado and Mattey (1997), in our model the increasing factor is attached to wages.
} 
distribution losses are assumed to evolve at the same pace as generation capacities efficiency improvement.

\section{Climate policies and Indian development: a deadlock?}

\subsection{Experimental protocol}

We use the IMACLIM-R model described in the previous section to develop scenarios with climate policies starting in 2013 so as to fit a given global emissions profile corresponding to stabilisation target at a concentration of 450ppm $\mathrm{CO} 2$. This places us in a "cost-efficiency" context.

For the setting of climate policies, we test, in this section, the prescriptions straightforward in a first best world: to equalize marginal abatement costs across countries with uniform carbon pricing so as to minimize the costs of a given environmental target. Two polar variants of climate regimes assure uniform carbon pricing: either a worldwide coordinated carbon tax or a global cap-and-trade system. The allocation of emission quotas in this second setting induces transfers between countries, therefore giving a lever on equity issues. In the following, we first consider a uniform carbon tax for all regions (Simulation 1); the level of this carbon tax is endogenously determined so that global emissions respect the emissions profile target. The carbon tax revenues are rebated to households in a lump-sum manner ${ }^{9}$. In a second step, we consider a global cap and trade system (Simulation 2). The quota system is represented by the assumption that countries auction emission permits and

\footnotetext{
${ }^{9}$ It has previously been show that the alternative uses of tax revenues, for instance to reduce other preexisting taxes, can change results significantly (Goulder, 1995; Bovenberg, 1999). It is also the case in our model (Guivarch et al, 2009), as we will see in the section 4 "Sensitivity analysis and robustness".
} 
return the revenues to households in lump-sum payments. Comparing these two simulations will allow us to separate the respective roles of the carbon pricing and of the international transfers due to quota allocation. The allocation rule chosen for Simulation 2 corresponds to a "Contraction and Convergence" (Meyer, 2000) of per capita emission at the 2100 horizon (CC2100), under a contracting global emission profile. This rule has been proposed as a bridge between the two polar rules: the grandfathering approach and the immediate equalitarian per capita criteria.

\subsection{Implications of sub-optimalities in the reference scenario and in mitigation} scenarios

Before describing and analyzing mitigation scenarios, we give a short description of major features of the baseline. An analyze of this reference scenario is detailed in Guivarch and Mathy, 2009.

The first major characteristic of the baseline is the fact that sub-optimalities in the power sector are long lasting. The power shortage persists due to the constraint on investment and the induced over-utilization of installed capacity drives to significant extra usage costs of electricity (the extra costs due to over-utilization of power generation capacities represent between $1.5 \%$ and $15 \%$ of production costs in the baseline scenario). As a consequence, industries are forced to resort to diesel generators to compensate for deficiencies of the centralized power supply. This limits the substitution from other energy sources, in particular oil, to electricity and constraint industrial production. 
The second characteristic is therefore India's economy dependency on oil, the majority of which is imported. The power sector deficiencies and the induced obstacles to substitution to electricity reinforce India's vulnerability to the rise of oil price. As a result India is deeply affected by its oil dependency: oil imports reach 10\% of GDP in 2027 when the oil prices rise steeply due to the beginning of the depletion phase of reserves.

The interplay between the structural capacity shortage of the power sector and the rising profile of oil prices drives to slower economic growth than in other existing prospective scenarios (IEA, 2007; Shukla 2006; EIA, 2007). In particular, economic growth declines significantly during the steep rise in oil price from 5.7\% GDP growth rate in 2019 to $3.8 \%$ in 2027 . GDP growth constrains energy efficiency improvement through the (limited) capacity to finance carbon sober technologies for productive capital or final equipment, and through the pace of capital vintages replacement: the lower the GDP growth, the lower the investment in new capital, the older is the average capital age, the worse its average energy efficiency. Therefore with important constraints on investments in the power sector, energy efficiency improvements are mechanically also constrained. As a result, energy decoupling of GDP and economic growth are much slower than in other existing scenarios (IEA 2006, 2007).

In mitigation scenarios, the electricity price increase and the overall activity decrease due to the macroeconomic impact of carbon pricing induces lower electricity demand significant enough to absorb the capacity shortage as soon as 2017 in Simulation 1 and 2020 in Simulation 2. But the pace of energy efficiency improvement in the power sector remains constrained by an even slower pace of capital vintage replacement. 
Moreover, subsidies mask incentives for end-use efficiency and maintain overconsumption habits. Given these implications of the power sector sub-optimalities in mitigation scenarios, we further investigate the macroeconomic impacts of mitigation policies in Simulations 1 and 2.

\subsection{A universal carbon tax: prohibitive costs for India}

The stabilisation objective leads to a world carbon price quasi-linear from 2013 to 2040, when it reaches $80 \mathrm{US} \$(2001) / \mathrm{tCO}_{2}$, and slightly decreasing to 65US $\$(2001) / \mathrm{tCO}_{2}$ in 2050 . These values are within the range depicted by existing modelling studies analysing stabilization around $450 \mathrm{ppmCO}_{2}: 30$ to $155 \mathrm{US} \$ / \mathrm{tCO}$ in 2050 (IPCC, 2007).

This carbon tax induces prohibitive macroeconomic costs for India (Figure 1): Indian GDP losses reach almost $20 \%$ of baseline GDP in 2030. These GDP losses are composed of (i) final consumption losses, (ii) trade losses (fewer exports and more imports) and (iii) less investment. Next paragraphs explore the mechanisms at stake in the evolution of the three components.

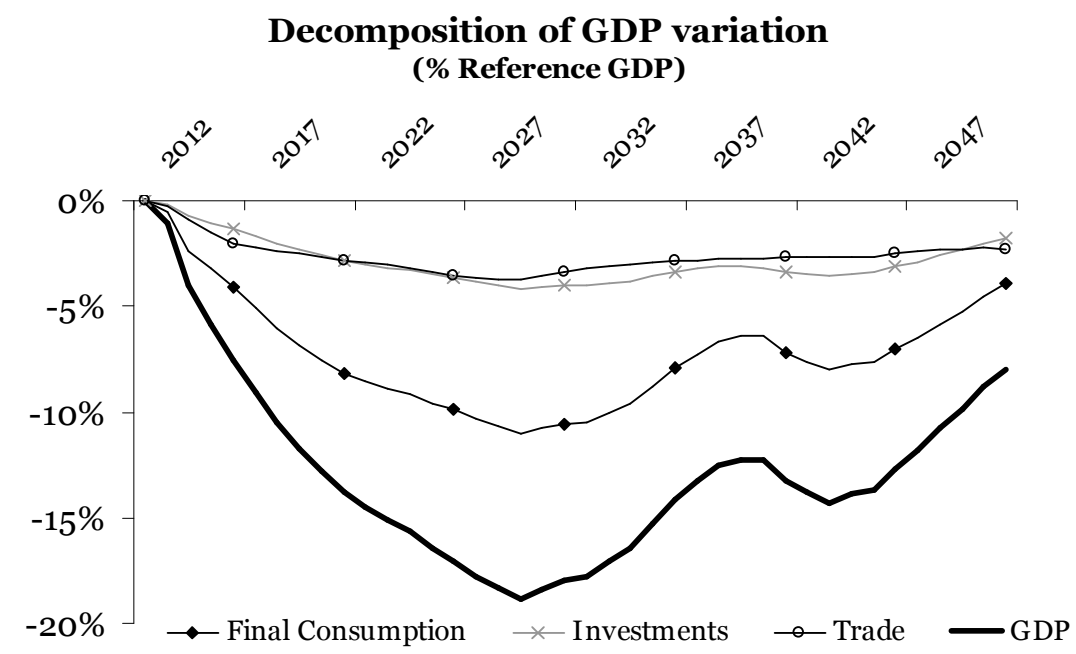


Figure 1: Decomposition of GDP variation between final consumption losses, decrease in investments and trade losses between Simulation 1 (uniform carbon tax) and the reference scenario.

First, final consumption losses come from the combination of (i) an increased energy budget for households, which crowds-out other goods consumption; and (ii) an income effect: the carbon tax rebated to households does not compensate the revenue losses due to less activity and lower real wages level ${ }^{10}$. Figure 2 gives the evolution of households budget share for non-energy goods consumption in the presence of the carbon tax compared to the reference scenario. It is reduced the first ten years after the introduction of the tax, but increases afterwards as technical change and consumption behaviour change away from carbon intensive goods are induced by carbon pricing. Households real income ${ }^{11}$ losses roughly follow the same profile as GDP losses profile and peak at $-18 \%$ in 2030 .
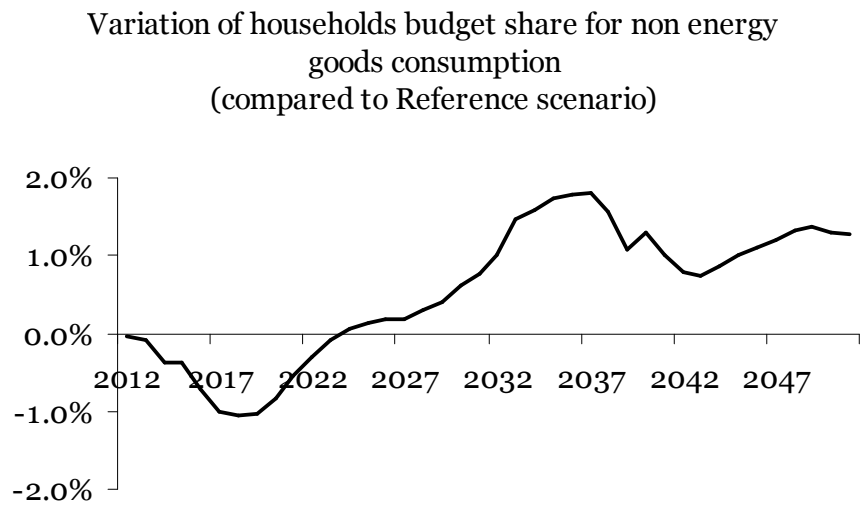

Figure 2: Evolution of household budget share for non energy goods consumption in Simulation 1 (uniform carbon tax) compared to the reference scenario.

Second, trade losses are due to competitiveness losses of Indian products following the introduction of carbon pricing. The competitiveness loss can be measured by the

\footnotetext{
${ }^{10}$ This latter effect comes from the representation of the labour markets through aggregate regional wage curves that link real wages to unemployment rates (Blanchflower and Oswald, 1995). See Guivarch et al (2009) for a detailed analysis of the implications of such a representation of labour markets imperfections on stabilisation costs.

${ }^{11}$ Households real income is their total revenue related to the final consumption price index.
} 
evolution of the ratio of the selling price on international markets to the local production cost (Table 2). Throughout the simulation period, the competitiveness index remains about 5\% inferior in simulation 1 than in the reference scenario. This competitiveness loss is due to higher energy share in industrial production costs in India than in other regions of the world. These effects are reinforced by persisting suboptimalities in the power sector and thus the high electricity usage costs for industry. Therefore production costs are relatively more affected by carbon pricing than in other regions.

And third, the investment term showed in Figure 1 follows the general economic activity, and is therefore reduced compared to the reference scenario.

Table 2: Evolution of the competitiveness index and of the electricity price in Simulation 1 (uniform carbon tax) compared to the reference scenario (reference scenario index=1). $20202030 \quad 2050$

\begin{tabular}{|llll|}
\hline Competitiveness index & 0.96 & 0.95 & 0.96 \\
Electricity price & 1.29 & 1.41 & 1.17 \\
\hline
\end{tabular}

If GDP losses reach dramatic levels around 2030, we may nonetheless note that Indian GDP losses are 'transition losses' over the period 2013-2050: they increase in the first part of the period and decrease in the second part. This latter decrease is due to (i) carbon tax induced technical change that lowers abatement costs and energy shares in production costs; but also to (ii) less vulnerability of the Indian economy to oil price rise at the end of the modelling period. 
The first element is illustrated in Table 22, which shows the evolution of the energy share in Indian industrial production costs over the 2012-2050 period in Simulation 1 compared to the reference scenario. It reveals that, at the end of the period, technical change induced by the global carbon tax leads to a lower energy share than in the reference case.

As for the second element, Guivarch et al. (2009) and Guivarch and Mathy (2009) showed that, in IMACLIM-R simulations, in the absence of specific policies such as subsidises to oil consumption or capital inflows, India is very vulnerable to a rise of international oil prices. This vulnerability is explained by mechanisms similar to those described above in the case of a carbon tax (loss of competitiveness due to high energy share in industrial production costs, crowding-out of other goods consumption by the energy burden, wage effect), aggravated by the transfer of income to oil exporting countries implied by higher oil prices. This vulnerability is reduced by climate policies for two reasons (Table 3). First, international oil prices are lowered by less global demand: compared to the baseline, oil prices are almost $30 \%$ lower in 2030 and $12 \%$ in 2050. Secondly, technical change and consumption structure change induced by climate policies reduce Indian dependence on imported. Table 3 shows indeed that Indian oil imports are $40 \%$ lower in value in 2030 and $20 \%$ lower in 2050 with climate policies compared to the reference scenario. This reduction of vulnerability to oil price rise can be explained by a better anticipation of oil tensions, thanks to earlier and more regular increases in final energy price. In a second-best world where anticipations are imperfect, indeed, brutal and unexpected increases in energy prices cause larger macroeconomic losses than regular and planned increases. Here, the more regular increase in energy price with climate policies prevents economic lock-in in an oil- 
dependent scheme and promotes the development of oil-free technologies before the beginning of the depletion phase in oil production.

Table 3: Variations, between Simulation 1 and the reference scenario, of the value of oil imports and decomposition of this variation between a price effect and a volume effect (second and third line)

\begin{tabular}{|lcc|c|} 
& $\mathbf{2 0 2 0}$ & $\mathbf{2 0 3 0}$ & $\mathbf{2 0 5 0}$ \\
\hline Oil imports (value) & $-31 \%$ & $-39 \%$ & $-17 \%$ \\
World oil price & $-20 \%$ & $-28 \%$ & $-11 \%$ \\
Oil imports & $-13 \%$ & $-15 \%$ & $-7 \%$ \\
(volume) & & & \\
\hline
\end{tabular}

This uniform carbon tax scenario reveals very significant economic impacts for India. The following sub-section analyses whether the financial transfers induced by a capand-trade system are able to reduce the costs of carbon pricing to an acceptable level for India.

\subsection{Quota allocations to solve equity issues?}

The second simulation considers a global cap-and-trade scheme with a 'Contraction and Convergence' (at the 2100 horizon) quotas allocation rule. With this allocation rule, India receives quotas equal to its emissions when the global cap-and-trade system is implemented; its per capita allocation increases to $0.4 \mathrm{tC} /$ cap in 2030 and decreases afterwards. Table 4 shows that the allocation rule becomes stringent before 2020 . The carbon price resulting from the implementation of the global cap-and-trade system induces effective emissions significantly lower than the allocation India receives with the contraction and convergence rule.

Table 4: Emission quotas allocated to India compared to the reference scenario emissions and effective emissions in Simulation 2 (in tons of carbon per capita). 


\begin{tabular}{|lccccc|}
\hline & $\mathbf{2 0 1 3}$ & $\mathbf{2 0 2 0}$ & $\mathbf{2 0 3 0}$ & $\mathbf{2 0 4 0}$ & $\mathbf{2 0 5 0}$ \\
\hline Reference scenario & 0.31 & 0.40 & 0.52 & 0.62 & 0.76 \\
Contraction and Convergence & 0.31 & 0.36 & 0.40 & 0.38 & 0.32 \\
Effective emissions & 0.31 & 0.27 & 0.26 & 0.24 & 0.24 \\
\hline
\end{tabular}

The carbon price emerging from this climate policy design is very close to that of the scenario with a global carbon tax. Financial transfers linked to quotas exchanges take place: India is a quota seller throughout the whole time horizon and receives up to $2.6 \%$ of its GDP from these sells (Table 5).

Table 5: Financial transfers received by India as a percentage of its GDP, compared to transfers received by other quotas sellers and paid by quota buyers as a percentage of their respective GDP.

\begin{tabular}{|lccc|c|} 
& $\mathbf{2 0 2 0}$ & $\mathbf{2 0 3 0}$ & $\mathbf{2 0 4 0}$ & $\mathbf{2 0 5 0}$ \\
\hline India & $1.5 \%$ & $2.6 \%$ & $2.3 \%$ & $0.6 \%$ \\
Other quota sellers & $0.4 \%$ & $1.0 \%$ & $1.4 \%$ & $0.4 \%$ \\
Quota buyers & $0,1 \%$ & $0,3 \%$ & $0,3 \%$ & $0,2 \%$ \\
\hline
\end{tabular}

Note: 1. The group of quota selling countries evolves with time. India, China, Brazil, Africa are quota sellers during the whole period; USA, Canada, Europe, OECD Pacific, FSU and Middle East are quota buyers during the whole period; Rest of Asia and Rest of Latin America are alternatively quotas sellers and quota buyers.

2. Figures related to quota buyers are inferior to figures related to quota sellers because of the difference in GDP levels between the two groups of countries.

In spite of the very significant transfers received ${ }^{12}$, India economy is still heavily affected the first fifteen years of the climate policies, with GDP losses reaching $6 \%$ of the reference scenario GDP in 2019 (Figure 3).

\footnotetext{
${ }^{12}$ To put these financial flows into perspective, Official Development Assistance (ODA) currently received by India represents about $0.3 \%$ of its GDP, and donor countries devote between 0.3 and $0.4 \%$ of their GDP to ODA.
} 


\section{Decomposition of GDP variation}

(\% Reference GDP)

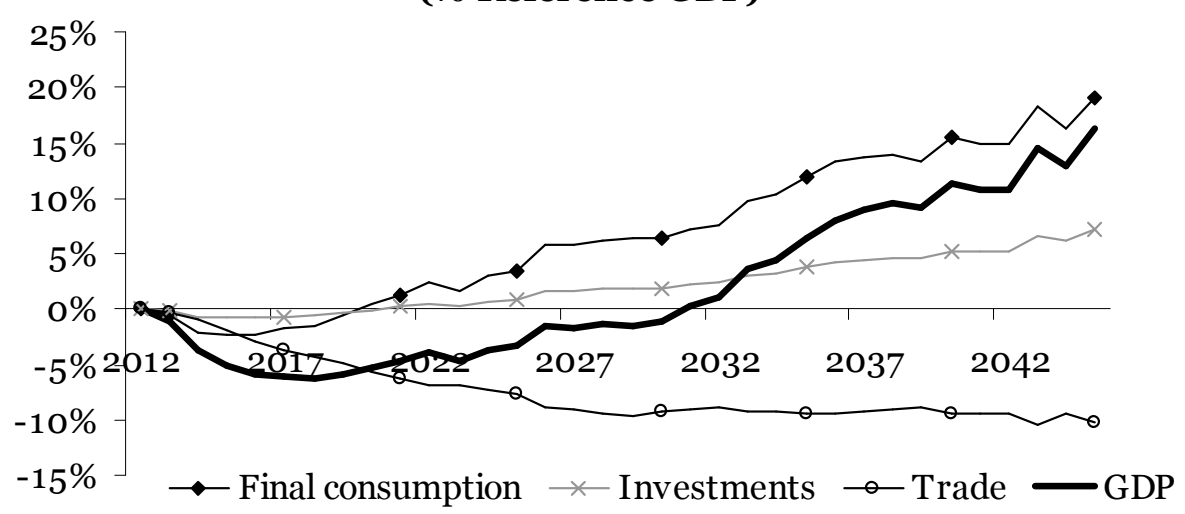

Figure 3 : Decomposition of GDP variation between final consumption losses, decrease in investments and trade losses between Simulation 2 (global cap-and-trade CC2100) and the reference scenario.

Two main elements due to capital inflows linked to quotas selling explain the differences from the scenario with a global carbon tax: (i) the income effect of quotas revenues, and (ii) the trade balance and real exchange rates effect due to quotas exchanges. On the one hand the revenues from quotas partially offset the revenue losses due to less activity and lower real wages level in the years following the introduction of carbon pricing, and contribute to the increase of final consumption. On the other hand, the capital inflow from quotas selling causes an appreciation of real exchange rates, which penalizes Indian products for exports and favours imported goods on domestic markets. This appreciation of real exchange rates corresponds to one of the symptoms of the so-called "natural resource curse" or 'Dutch Disease', which have been observed in most oil-producing countries (Sachs and Warner, 2001), and has previously been highlighted in the case of capital flows due GHG quotas exchanges by McKibbin et al. (2000).

The resulting time profile of GDP variation (Figure 3) shows that financial transfers due to quotas selling do not offset the negative macroeconomic effect of 
competitiveness losses and crowding out of non energy goods consumption, during a transition period. After 2030, however, the positive macroeconomic effect of financial inflows dominates and Indian GDP becomes higher than in the reference scenario.

The transition macroeconomic losses happen when the carbon price is still low and when allocations are still close from the grandfathering allocation rule. One solution could be to define another allocation rule generating more financial transfers towards India in the early years of implementation of the cap-and-trade scheme. Nevertheless, high transfers face a credibility gap ${ }^{13}$ and that have little chance to be acceptable for Annex I countries (Jacoby et al., 2008). Moreover, this solution would not solve the issue of real exchange rate appreciation due to large amount of financial inflows in India.

In the following we propose an alternative scenario based on Indian domestic policies targeting sub-optimalities in the power sector.

\section{Looking for synergies between climate policies and development}

\subsection{Further simulations}

This part explores a 'package of domestic policies and measures' implemented in India jointly with the participation to the global cap and trade system. The domestic policies we consider are meant to reduce transition economic losses due to the international mitigation policy and to create synergies between mitigation policies and development policies in India. As it was highlighted that sub-optimalities in the power sector hinder both growth and energy efficiency (Guivarch and Mathy, 2009), the

\footnotetext{
${ }^{13}$ One should not forget that donor countries committed themselves to dedicate $0.7 \%$ of their GDP to Official Development Assistance (ODA), but do not respect this commitment, only dedicating $0.4 \%$ of their GDP dedicated to ODA.
} 
policies considered are specifically targeting these sub-optimalities. In the following simulation (Simulation 3), the focus is on combining (i) electricity tariff reforms in the agricultural sector accompanied by demand side management measures, and (ii) efficiency of the power sector. Indeed, literature on energy issues in India shows the need for a tariff reform so that prices better reflect costs (Filippini and Pachauri, 2004). In addition to giving energy savings incentive, it would increase revenues for the power sector. However, to overcome strong social and political obstacles to a tariff reform, it appears, as pointed out by Bose et al. $(2006)^{14}$, that it has to be combined with an ambitious program improving the power supply quality.

In practice, the alternative scenario we consider still follows global emissions profile corresponding to stabilisation target at a concentration of 450ppm $\mathrm{CO} 2$, and assumes a global cap and trade system starting in 2013 with quota allocations based on the CC2100 rule, as in the preceding section. The 'package of domestic policies and measures' is assumed to start also in 2013 and encompasses:

The progressive reduction of subsidies to electricity consumption for the agricultural sector, accompanied by demand side management (improvement of irrigation pumps, evolution of consumption habits ${ }^{15}$ ). Following the reform suggested by the World Bank (2001), it is assumed that on the one hand, the subsidies decrease and the unit price increases, but on the other hand, the consumption level decreases. This joint evolution is supposed to occur at a constant budget for electricity for farmers and to reach a cut of $50 \%$ of the subsidies to electricity consumption for the agricultural sector, over a 10 year period.

\footnotetext{
${ }^{14}$ Bose et al. (2006) evaluate for different consumer categories their willingness to pay more for a better supply quality (with less shortage) in the Karnataka region.

${ }^{15}$ In particular, if the grid quality and the service are improved, the number of unpredictable power cuts will be significantly lower, and farmers will not have to leave their pumps switched on all day long.
} 
- The implementation of a program to reduce electricity $T \& D$ technical and commercial losses. This program would partly be composed of refurbishment of obsolete installations of power distribution all around the country but also of new managerial methods to reduce commercial losses (details of such a program can be found in IEA, 2002). The cost and the potential for improvement are calibrated on Ruet (2001). The level of T\&D losses decreases to $15 \%$ over a 20 year period.

- The revenues following the partial removal of electricity consumption subsidies in the agricultural sectors are used to finance the demand side management program in the agricultural sector, the reduction of technical and commercial losses in electricity $\mathrm{T} \& \mathrm{D}$, and the additional power generation capacities if needed. Remaining additional revenues, if any, are rebated to households through lump-sum transfers.

\subsection{Results}

Figure 4 focuses on the transition and shows the Indian GDP variation between Simulation 3 and the reference scenario for the first two decades after policies introduction.

\section{Decomposition of GDP variation (\% Reference GDP)}

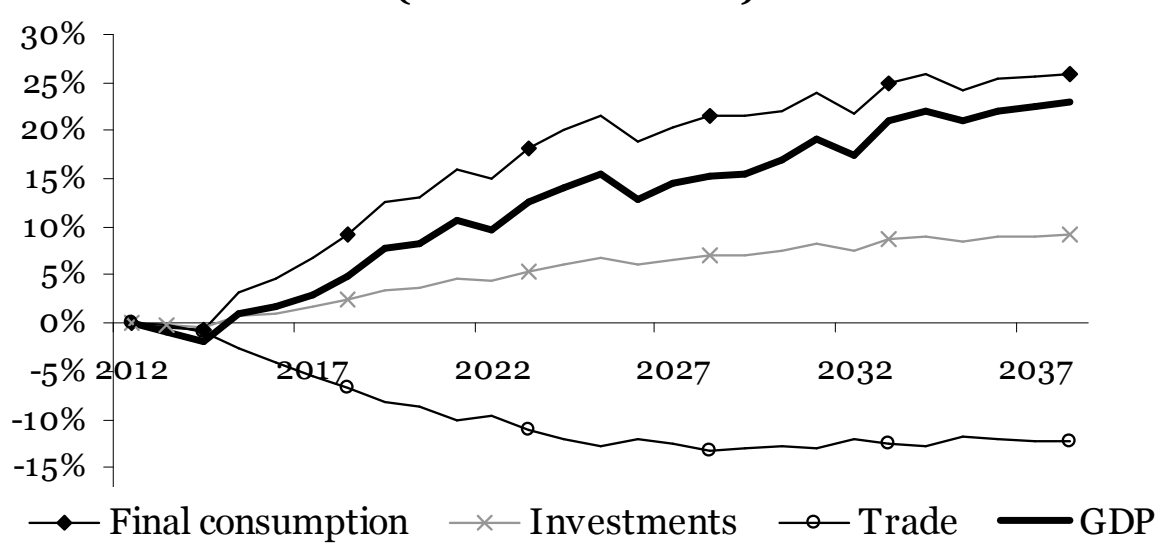

Figure 4 : Decomposition of GDP variation between final consumption losses, decrease in investments and trade losses between Simulation 3 (global cap-and-trade CC2100 with package of domestic policies in India) and the reference scenario. 
In this simulation, Indian GDP losses are confined to the first three years after the start of mitigation policies and peak GDP losses are limited to $2 \%$ of the reference scenario GDP. These lower macroeconomic costs of the international mitigation policy than in Simulation 2 are brought by the package of domestic policies and measures via three main channels.

First, the reduction of electricity $\mathrm{T} \& \mathrm{D}$ losses decreases the electricity usage cost by 4\% in 2015, 5\% in 2020 and $8 \%$ in 2030 in Simulation 3 compared to Simulation 2. This cost decrease induces substitution from fossil fuels to electricity in the industry section, which leads to a lower share of energy budget in industrial production costs. Therefore Indian products lose relatively less competitiveness in this simulation than in Simulation 2, and salaries are less squeezed to restore commercial balance: wage levels are 3\% higher than in Simulation 2 in 2015, and 9\% in 2020 and 2030.

Second, the same decrease of electricity usage cost reduces households energy budget share, which leads to less crowding-out of other goods consumption. However, this effect is non monotonous as it derives from complex interactions between energy prices, revenues dynamics and equipment dynamics (personal vehicles ownership for instance): between Simulations 2 and 3, households energy budget shares are reduced by 0.7 percentage point in 2015, 0.4 in 2020 and 0.5 in 2030 .

Third, there is a positive income effect stemming from higher wage levels, more wages volume due to more overall activity and transfers to households coming from the remaining revenue generated by subsidies decrease not used to finance the domestic policies and measures (which represent up to $0.4 \%$ of GDP in the Simulation).

These results show that the package of domestic policies and measures considered in this scenario reduces significantly the magnitude and duration of transition 
macroeconomic losses due to international mitigation policies. While last sections aimed at disentangling the cost formation mechanisms under alternative policy settings, next section will test the robustness of the results through a sensitivity analysis to the model parameterization.

\section{Sensitivity analysis and robustness}

In this antepenultimate section we reproduce the same policies setting as in Simulation 1, 2 and 3 with alternative parameterization of the model to take into account the uncertainties on a large set of exogenous parameters. The uncertain parameters include inter alia: the amount of fossil fuel reserves, the coal market responsiveness to demand increase, the rhythm of technical change (date of availability of low carbon technologies such as carbon capture and sequestration, rate of learning by doing, etc.), the synfuels supply curve characteristics and its evolution, the future development styles (rate of car ownership increase when revenue increase for instance). A detailed description of these parameters and the method used to conduct a sensitivity analysis is given in Vogt-Schilb et al. (2009). Climate policies international architecture is either a uniform carbon tax (as in Simulation 1) or a global cap-and-trade scheme with emission quotas allocated following the CC2100 rule (as in Simulation 2). Domestic policies are either uniform carbon pricing alone (as in Simulation 1 and 2) or in parallel with the package of domestic policies and measures focussing on electricity tariff reform for the agriculture sector and on efficiency in the power sector (as in Simulation 3). Moreover, we test alternative uses of carbon pricing revenues: they are either rebated to households in a lump-sum manner or used to reduce other taxes. 
Figure 5 confirms that a global carbon tax implies prohibitive costs for India: the mean peak GDP loss is $10.8 \%$ of reference GDP, with results ranging between $4.7 \%$ and 24.3\%. We may note this result varies significantly with the use of carbon pricing revenues: the mean peak GDP loss is $15.7 \%$ of reference GDP when carbon revenues are rebated to households and $8.1 \%$ when they are used to reduce other taxes.

\section{Indian GDP variation (\% Reference) International Carbon Tax}

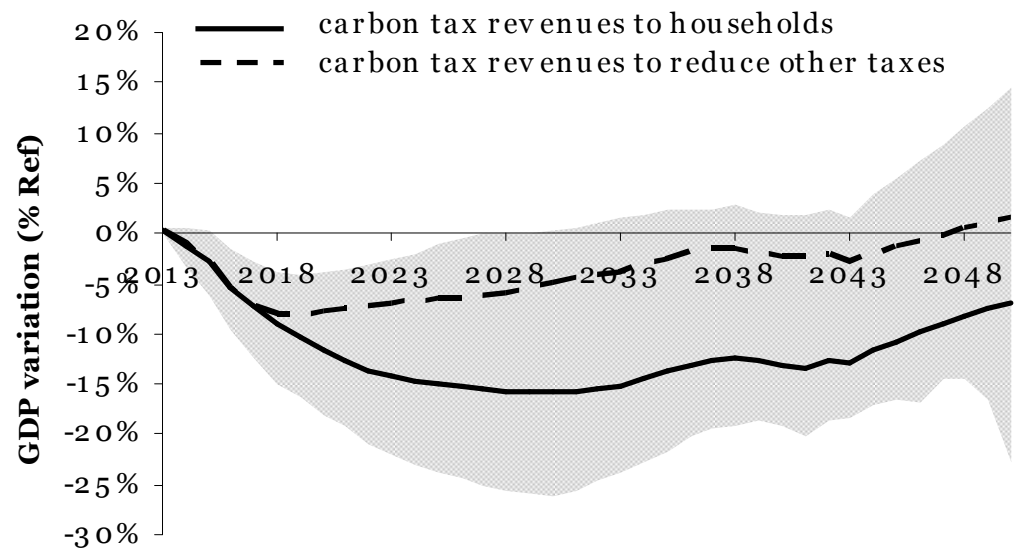

Figure 5: Range of Indian GDP variation when a global uniform carbon tax is introduced (\% of corresponding reference GDP). The shaded area gives the full range of variation for the alternative parameterization of the model tested, the plain line gives the mean across scenarios where the carbon tax revenues are rebated to households and the dashed line gives the mean across scenarios when they are used to reduce other taxes.

Figure 6 (left panel) shows that a global cap and trade system with CC2100 quota allocation rule does not solve the transition cost issue. Indeed, the mean duration of GDP losses is 9 years, with results ranging from 5 to 21 years, and the magnitude of peak GDP loss ranges from $2.3 \%$ of reference GDP to $10.9 \%$, with a mean value equal to $4.8 \%$. In this policy setting again the use of carbon pricing revenues influences significantly the results: the duration of GDP loss is reduced on average by 4 years when revenues are used to reduce other taxes compared to the cases when they are rebated to households in a lump-sum manner. 
Figure 6 (right panel) shows the robustness, in alternative future worlds, of the package of domestic policies and measures considered in this study to reduce the transition macroeconomic losses for India following the introduction of a global capand-trade scheme. The duration of macroeconomic losses is limited to 5 years on average, extremes being 0 years and 15 years. The magnitude of the peak GDP loss is reduced by 3.7 percentage point on average.
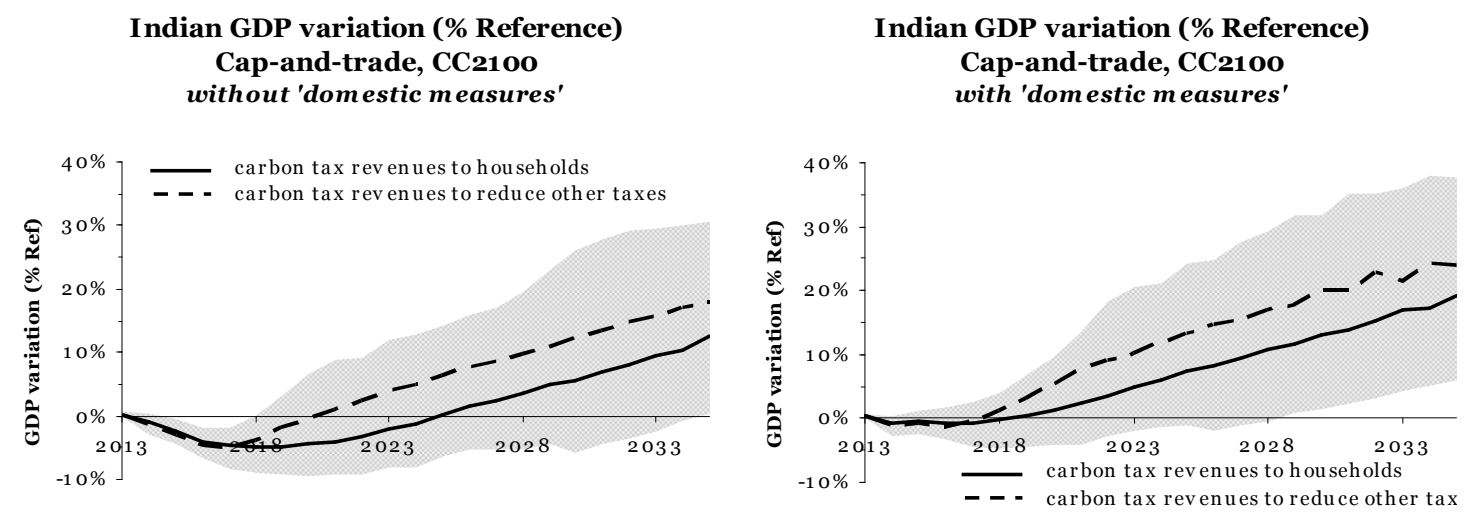

Figure 6: Range of Indian GDP variation when a global cap-and-trade scheme is introduced ( $\%$ of corresponding reference GDP). The left panel gives the range for scenarios where domestic policies are uniform carbon pricing alone (as in Simulation 2), while the right panel gives the range for scenarios including the package of domestic policies and measures focussing on electricity tariff reform for the agriculture sector and on efficiency in the power sector (as in Simulation 3). The shaded area gives the full range of variation for the alternative parameterization of the model tested, the plain line gives the mean across scenarios where the carbon tax revenues are rebated to households and the dashed line gives the mean across scenarios when they are used to reduce other taxes.

Figure 7 shows histograms and smoothed densities of peak GDP losses (in \% of reference scenario GDP) with and without the package of domestic policies and measures considered in this article. With the package of domestic policies and measures the histogram is shifted to the left, indicating that these domestic policies reduce the macroeconomic transition losses for India following the introduction of a global cap-and-trade scheme. Moreover the right tail of the peak GDP loss distribution is shortened: the domestic policies avoid cases with very large GDP losses. 


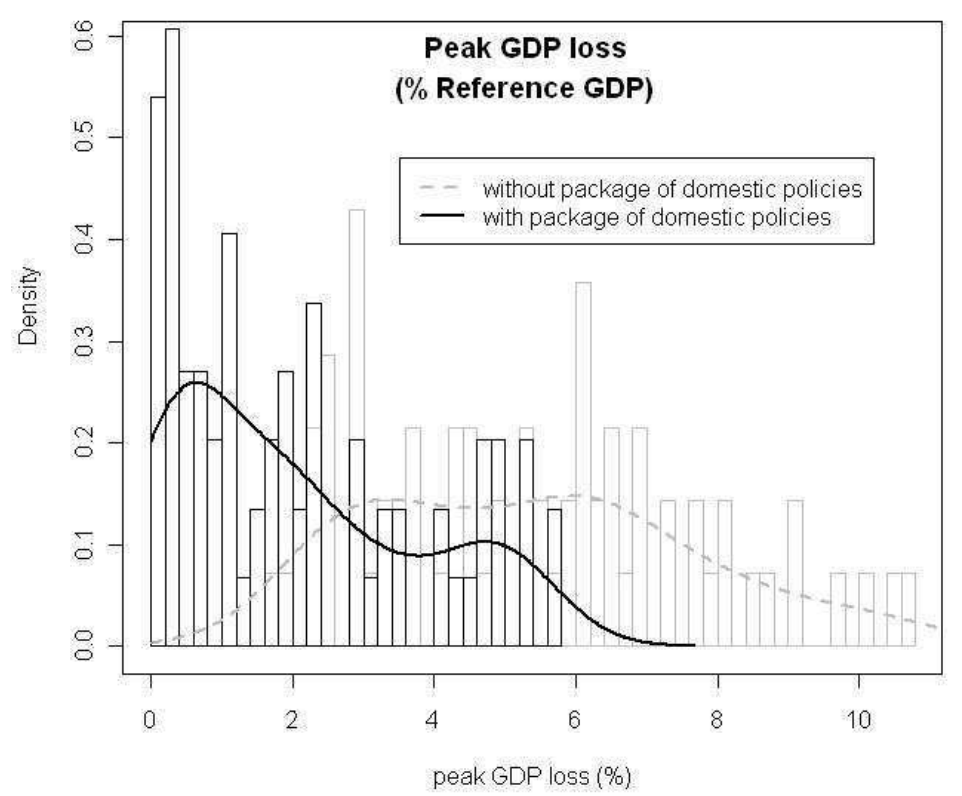

Figure 7 : Histogram and smoothed densities of Indian peak GDP losses (in \%) due to mitigation policies. Grey bars and dashed line corresponds to scenarios where domestic policies are uniform carbon pricing alone, while black bars and plain line corresponds to scenarios including the package of domestic policies and measures focussing on electricity tariff reform for the agriculture sector and on efficiency in the power sector.

\section{Conclusion}

To conclude, we may first summarize the findings of the modelling exercises explored in this article. First, it appears that global carbon pricing induces prohibitive macroeconomic costs for the Indian economy, even in the case of significant financial transfers associated with a "Contraction and Convergence in 2100" allocation scheme. Second, we identified a 'package of domestic policies and measures' focussing on combining (i) electricity tariff reforms in the agricultural sector accompanied by demand side management measures, and (ii) efficiency of the power sector. We showed that this package of domestic policies and measures allows reducing significantly both the duration and the magnitude of India GDP losses following the introduction of the global cap-and-trade system. This analyse confirms, in the case of India that policies focusing on the current sub-optimalities of the power sector appear 
as a centre piece of domestic development policies in the context of global mitigation policies.

We acknowledge that this study is limited because of the focus on the power sector only. Conclusions regarding the potential for implementing synergies between development and mitigation could be reinforced by considering a larger panel of sectors. Further research is needed to broaden the scope of sectors and types of domestic policies and measures considered. Moreover, the time sequence of policies and entry into a global agreement should be analysed.

Nethertheless, two strong messages can be drawn from our results. First, from a methodological point of view, our approach calls for the representation of second-best mechanisms and of national specificities in modelling frameworks used to assess climate policies. Second, from a policy point of view, our results open room for synergies between mitigation policies and development. At the core of these synergies, appears the crucial role of domestic policies and measures focusing on removing energy consumption subsidies and enhancing energy efficiency, and adapted to national specificities. This result suggest rephrasing the issue for international climate policies from the question of the fairness of burden sharing to the design of an architecture in which climate policies could contribute to development over the long run but also here and now.

\section{Acknowledgements}

The authors wish to thank Jean-Charles Hourcade, Stéphane Hallegatte and Olivier Sassi for their useful comments and suggestions on a previous version of this article, as well as all the team who contributed to IMACLIM-R development. We are also 
grateful to two anonymous referees whose comments helped us improve this text significantly. Part of this article is based on studies that have benefited from financial support from the GICC (Gestion et Impacts du Changement Climatique) research program of the French environmental department.

\section{References}

Barker, T., Koehler, J., Villena, M., 2002. The costs of greenhouse gas abatement: A meta-analysis of post-SRES mitigation scenarios. Studies 5: 135-166.

Bovenberg, A., 1999. Green Tax Reforms and the Double Dividend: an Updated Reader's Guide," International Tax and Public Finance, Springer, vol. 6(3), pp. 421443,

Barro, R. J., Sala-i-Martin, X. 1992. Convergence. Journal of Political Economy 100, no. 2: 223.

Blanchflower D.G, Oswald A.J., 1995. Estimating a wage curve for Britain 19731990, NBER Working paper 4770

Bose, R.K., Shukla, M., Srivastava, L., Yaron, G., 2006. Cost of unserved power in Karnataka, India. Energy Policy 34, 1434-1447.

Corrado, C., Mattey, J., 1997. "Capacity Utilization”, Journal of Economic Perspectives, Vol. 11, No. 1, pp. 151-167. 
Dimaranan, B. V., McDougall, R. A.. 2002. Global trade, assistance, and production: The GTAP 5 data base. Center for Global Trade Analysis, Purdue University.

Dorin, B., Jullien, T., 2004. Agricultural incentives in India. Past trends and prospective paths towards sustainable development. Manohar, New Delhi.

Edmonds, J., Pitcher, H., Sands, R., 2004. Second General Model 2004: An Overview. Joint Global Change Research Institute, College Park, MD Pacific Northwest National Laboratory.

Energy Information Administration (EIA), 2007. International Energy Outlook 2007. Office of Integrated Analysis and Forecasting, U.S. Department of Energy, Washington, DC. 230pp.

Filippini, M., Pachauri, S., 2004. Elasticities of electricity demand in urban households. Energy Policy 32, 429-436.

G8 declaration, 2009. Responsible leadership for a sustainable future, 49pp. Available at http://www.g8italia2009.it/static/G8_Allegato/G8_Declaration_08_07_09_final,0.pdf

Government of India, 2008. Economic Survey 2007-08. http://indiabudget.nic.in. 
Guivarch, C., Hallegatte, S., Crassous, R., 2009. The Resilience of the Indian Economy to Rising Oil Prices as a Validation Test for a Global Energy-EnvironmentEconomy CGE Model. Conference on the International Dimensions of Climate Policies, 21 - 23 January 2009, University of Bern, Bern, Switzerland.

Guivarch, C., Mathy, S., 2009. "What if energy decoupling of emerging economies were not so spontaneous? An illustrative example on India", Working paper CIRED. Available at : http://www.centre-cired.fr/spip.php?article803

Intergovernmental Panel on Climate Change, 2007. Climate Change 2007: Mitigation. Contribution of Working Group III to the Fourth Assessment Report of the Intergovernmental Panel on Climate Change [B. Metz, O.R. Davidson, P.R. Bosch, R. Dave, L.A. Meyer (eds)], Cambridge University Press, Cambridge, United Kingdom and New York, NY, USA.

International Energy Agency, 2002. Electricity in India - providing power for the millions. OCDE/IEA. Paris.

International Energy Agency, 2006, World Energy Outlook. OCDE/IEA. Paris.

International Energy Agency, 2007, World Energy Outlook. OCDE/IEA. Paris.

Jacoby, H.D., Babiker, M.H., Paltsev, S., Reilly, J.M., 2008. Sharing the burden of GHG reductions. Joint Program Report Series, Report 167, Nov 2008. 
Jintao, H., 2009. Join Hands to Address Climate Challenge. Statement by H.E. Hu Jintao, President of the People's Republic of China at the opening Plenary Session of the United Nations Summit on Climate Change. New York, 22 September 2009. Available at: http://www.un.org/wcm/webdav/site/climatechange/shared/Documents/China.pdf

Hatoyama, Y., Prime minister of Japan, 2009. Statement by H.E. DR. Yukio Hatoyama Prime minister of Japan at the United Nations Summit on Climate Change, New York, 22 September 2009. 4pp.

LEPII-EPE, 2006. The POLES model, POLES State of the Art. Institut d'Économie et de Politique de l'Énergie, Grenoble, France. Available at: http://upmfgrenoble.fr/iepe/Recherche/Rech5.html

Maddison, A., 1995. Monitoring the world economy: 1820 - 1992. OECD Development

Center.

Manne, A., Richels, R., 1997. On stabilizing CO 2 concentrations-cost effective emission reduction strategies. Environmental Modeling and Assessment 2, no. 4: 251265.

Martins, J.O., Gonand F., Antolin P., De La Maisonneuve C., Yoo K.Y. 2005. The Impact of Ageing on Demand, Factor Markets and Growth. OECD Economics Department Working Papers 420 (March 29) 
McKibbin, W., Ross, M., Shackleton, R., Wilcoxen, P., 2000. Emissions trading, capital flows and the Kyoto Protocol. Energy Journal 21: 287-334.

Meyer, A, 2002. Contraction and convergence, the solution to climate change, Schumacher Briefing $N^{\circ} 5$, Green Books.

Paltsev, S., Reilly, J.M., Jacoby, H.D., Eckaus, R.S., McFarland, J., Sarofim, M., Asadoorian, M., Babiker, M., 2005. The MIT Emissions Prediction and Policy Analysis (EPPA) Model: Version 4. MIT Joint Program Report 125.

Ruet, J., 2001. Investment profitability in bridging the power gap in India. The Indian Economic Journal. October-December. Volume 49, n². 17p.

Sachs J.D., Warner, A.M. 2001. The curse of natural resources. Natural Resources and Economic Development. 45:4-6. pp.827-838.

Sands, R. D., Miller, S., Kim, M.K., 2005. The Second Generation Model: Comparison of SGM and GTAP Approaches to Data Development . PNNL report no. 15467 .

Sassi, O., Crassous, R., Hourcade, J.-C., Gitz, V., Waisman H., Guivarch, C., 2007. IMACLIM-R: a modeling framework to simulate sustainable development pathways. International Journal of Global Environmental Issues (accepted). 
Shukla, P. R., 1995. Greenhouse gas models and abatement costs for developing nations. A critical assessment. Energy Policy 23, no. 8: 677-688.

Shukla, P.R., 2006. India's GHG emission scenarios: Aligning development and stabilization paths. Current Science, 90(3), 10 February 2006.

Solow, R.M., 1956. A Contribution to the Theory of Economic Growth. Quarterly Journal of Economics, vol. 70, nº 1, 1956, p. 65-94.

Solow, R., 2000. Toward a macroeconomics of the medium run, Journal of Economic Perspectives 14 (1), pp. 151-158.

Stavins, R.N., Jaffe J.L., Schatzki T. (2007). Too Good to Be True? An Examination of Three Economic Assessments of California Climate Change Policy. SSRN eLibrary (January). http://papers.ssrn.com/sol3/papers.cfm?abstract_id=973836

Thakur, T., Deshmukh, S.G., and Kaushik, S.C., 2006. Efficiency evaluation of the state owned electric utilities in India, Energy Policy 34, 2788-2804.

Tongia, R. and R. Banerjee, 1998. Price of Power in India, Energy Policy, 26, 557575.

Urban, F., Benders, R.M.J., Moll. H.C., 2007. Modelling energy systems for developing countries. Energy Policy 35, no. 6: 3473-3482. 
van Ruijven, B., Urban, F., Benders, R.M.J., Moll, H.C., van der Sluijs, J.P., de Vries, B., van Vuuren, D.P., 2008. Modeling Energy and Development: An Evaluation of Models and Concepts. World Development 36, no. 12: 2801-2821.

Urban, F., Benders, R., Moll, H., 2007. Modelling energy systems for developing countries. Energy Policy, 35, 3473-3482.

Vogt-Schilb, A., Rozenberg, J., Sassi, O., 2009. Methodology for scenarios development and sensitivity analysis with Imaclim-R. Cired Working Paper.

Weyant, J.P., Hill, J.N. 1999. "Introduction and Overview." The Energy Journal Special Issue: The Costs of the Kyoto Protocol: A Multi-Model Evaluation, pp. viixliv.

World Bank, 1998. Power sector reform and the privatization of distribution in India. Internal working document prepared by H. Salgo et al. March 1998.

World Bank, 2001. India - Power supply to agriculture. Energy sector Unit, South Asia regional office. Report No 22171-IN. 